\title{
Serum Antibodies against Helicobacter pylori Neutrophil Activating Protein in Carriers of IL-4 C-590T Genetic Polymorphism Amplify the Risk of Gastritis and Gastric Cancer
}

\author{
Yeganeh Talebkhan ${ }^{* * 1}$, Mohsen Doozbakhshan ${ }^{* * 1}$, Samaneh Saberi ${ }^{1}$, Maryam Esmaeili ${ }^{1}$, \\ Najmeh Karami ${ }^{1}$, Nazanin Mohajerani ${ }^{1}$, Afshin Abdirad ${ }^{2}$, Mahmoud Eshagh Hosseini ${ }^{3}$, Azin \\ Nahvijou ${ }^{4}$, Mohammad Ali Mohagheghi ${ }^{4}$ and Marjan Mohammadi ${ }^{* 1}$ \\ ${ }^{1}$ HPGC Group, Department of Medical Biotechnology, Biotechnology Research Center, Pasteur Institute of \\ Iran, Tehran, Iran; ${ }^{2}$ Cancer Institute, Tehran University of Medical Sciences, Tehran, Iran; \\ ${ }^{3}$ Department of Gastroenterology, Amiralam Hospital, Tehran University of Medical Sciences, Tehran, \\ Iran; ${ }^{4}$ Cancer Research Center, Tehran University of Medical Sciences, Tehran, Iran
}

Received 20 August 2016; revised 5 September 2016; accepted 21 September 2016

\begin{abstract}
Background: Gastric cancer arises, mainly, on an inflammatory background. Helicobacter pylori neutrophil activating (HP-NAP) protein functions as a potent pro-inflammatory mediator. Similarly, IL-4 plays a critical role in the inflammation pathway, the levels of which are altered by $C$ to $T$ transition at position -590 in its promoter region. Here, we have aimed to assess the risk of gastritis and gastric cancer in the co-presence of these two inflammation modulating mediators. Methods: Gastritis $(n=58)$ and gastric cancer $(n=31)$ patients were evaluated and compared with $H$. pylori-positive asymptomatic controls $(n=46)$, for serum antibodies against recombinant HP-NAP and IL-4 C-590T single nucleotide polymorphism using immunoblotting and PCR-RFLP, respectively. Multivariable logistic regression, adjusting for age, gender and ethnicity, was used for data analysis. Results: In terms of susceptibility to gastritis, seropositivity to HP-NAP projected a risk impact of 4.62 fold ( $\mathrm{OR}=4.62,95 \% \mathrm{Cl}=1.50-14.22$ ), which when present in IL-4 $-590 \mathrm{~T}$ carriers augmented the risk up to 9.7 fold (OR=9.70, 95\% Cl=2.06-45.69). A similar pattern, but of a stronger magnitude, occurred for the risk of gastric cancer, which was estimated at 9.07 fold $(\mathrm{OR}=9.07,95 \% \mathrm{Cl}=1.99-42.0)$ for HP-NAP-seropositive subjects and was drastically amplified (OR=33.64, 95\% Cl=2.06-548.68), when double-positive (HP-NAP seropositive/IL-4 -590 T carrier) subjects were examined against double negatives (HP-NAP seronegative/IL-4 -590 CC). Conclusion: Our preliminary data indicate that serum antibodies against HP-NAP represent a state of risk, which is further exacerbated in IL-4 -590 T carriers. These biomarkers, if validated in larger prospective studies, can be used to screen for gastric cancer susceptibility. DOI: 10.18869/acadpub.ibj.21.5.321
\end{abstract}

Keywords: Biomarkers, Genetic Polymorphism, Recombinant

Corresponding Author: Marjan Mohammadi

HPGC Group, Department of Medical Biotechnology, Biotechnology Research Center, Pasteur Institute of Iran, Tehran 1316943551, Iran; Tel. \& Fax: (+98-21) 66480780; E-mail: marjan.mohammadi@ pasteur.ac.ir

** Yeganeh Talebkhan and Mohsen Doozbakhshan share first authorship.

\section{INTRODUCTION}

$H$ elicobacter pylori infect nearly half of the world population, the majority of which remain asymptomatic. However in a small fraction $(2-3 \%)$, infection leads to gastric cancer ${ }^{[1]}$. According to a recent study in a low-risk population, the transition of infected individuals through the so- called Correa cascade ${ }^{[2]}$ increases their risk of developing gastric cancer, from $0.3 \%$ in those with normal mucosa; to $1.1 \%$ in gastritis patients; to $2 \%$ in atrophic gastritis; to $2.5 \%$ in intestinal metaplasia; and finally up to $5.2 \%$ in those with dysplasia ${ }^{[1]}$. There are a multitude of factors originating from the pathogen, host, and environment as well as their interactions, which come together to create grounds for the 
development of gastric cancer.

H. pylori produce a diverse repertoire of virulence factors. Amongst its highly immunogenic and proinflammatory antigens is the HP-NAP protein, known for its activation of neutrophils ${ }^{[3]}$. HP0243 is the gene encoding the $17-\mathrm{kDa}$ subunit, which oligomerizes into the $150-\mathrm{kDa}$ dodecameric structure of HP-NAP with a hollow internal core ${ }^{[4]}$. This conserved gene is differentially expressed amongst different $H$. pylori strains ${ }^{[4-6]}$. The most studied function for HP-NAP is recruitment and activation of neutorphils and monocytes and subsequent production of reactive oxygen intermediates ${ }^{[4,7]}$, mediated by the activation of phagocytic NADPH-oxidase. A repertoire of other diverse functions has also been attributed to this protein which includes: (1) DNA binding ${ }^{[8]}$ and protection from oxidative damage ${ }^{[6,9]},(2)$ adhesion to mucins and mucosal surfaces ${ }^{[10]}$, (3) iron-binding capability (up to 500 atoms) ${ }^{[11]}$, (4) urease-independent acid resistance ${ }^{[12]}$, and (5) immune activation with a pro-Th1 and anti-Th2 modulation and adjuvanticity ${ }^{[3,13-}$ 18] and has been demonstrated in different disease models. Host serum antibodies against HP-NAP are variably present in different populations ${ }^{[19-22]}$ and have been associated with the risk of gastrointestinal complications including gastric cancer ${ }^{[23,24]}$. IL-4, on the other hand, takes precedence in its immunemodulating function and Th2 polarizing capacity. The Th1/Th2 balance and its pro- and anti-inflammatory downstream effects, although seemingly contradictory, are both documented in the gastric carcinogenic process $^{[25,26]}$. The most frequent genetic alteration in the IL-4 gene occurs at position -590 in its promoter region. The $\mathrm{C} / \mathrm{T}$ polymorphism at -590 position (rs 2243250) is associated with altered levels of IL-4 expression $^{[27]}$. In parallel, the prevalence of gastric cancer is controversially reported to be associated with this genetic polymorphism ${ }^{[28-30]}$.

In order to address the synergistic risk impact of these two inflammation-modulating mediators, we have assessed the independent and joint presence of serum antibodies to HP-NAP (originating from the pathogen) and IL-4 -590C/T SNP (originating from the host) in gastritis and gastric cancer patients, in comparison with $H$. pylori-positive asymptomatic controls.

\section{MATERIALS AND METHODS}

\section{Production of recombinant HP-NAP}

Amplification of HP-NAP gene fragment from $H$. pylori genomic DNA was carried out by PCR using the following forward (5'-GTCATATGAAAACATTT GAAATTTTAAAAC-3') and reverse (5'-GTCTCGA
GAGCCAAATGG-3') primers, under the following conditions: one cycle of initial denaturation $\left(95^{\circ} \mathrm{C}, 5\right.$ min), followed by 30 cycles of $95^{\circ} \mathrm{C}(1 \mathrm{~min}), 50^{\circ} \mathrm{C}(30$ $\mathrm{s}), 72^{\circ} \mathrm{C}(1 \mathrm{~min})$ and terminated by one cycle of final extension $\left(72^{\circ} \mathrm{C}, 5 \mathrm{~min}\right)$. The amplified PCR product was cloned into pTZ57R T-vector(Promega, USA) and transformed into $E$. coli TOP10F' strain (Invitrogen, USA). NdeI/XhoI-digested pET23a expression vector (Invitrogen, USA) was used for subcloning and transformation into $E$. coli BL21 (DE3) strain (Invitrogen, USA). Restriction digestion and partial sequencing were used to confirm the identity of the cloned gene fragment. Protein expression was induced by $0.5 \mathrm{mM}$ IPTG during 4 hours of culture in LB broth. Western blotting using anti-6X His tag antibody (Roche, USA) and pooled $H$. pylori-positive and -negative sera were used to confirm the identity of the recombinant protein.

\section{Subjects}

Our study population included 135 subjects categorized as follows: A) gastric cancer patients $(n=31$ : age range $=59.4 \pm 11.6, \quad M: F=21: 10$; Cancer Research Center, Tehran, Iran), B) gastritis patients $(\mathrm{n}=58$ : age range $=56.5 \pm 9.4, \mathrm{M}: \mathrm{F}=30: 28$; Amiralam Hospital, Tehran, Iran), and C) H. pylori-positive asymptomatic volunteers $(n=46$ : age range $=52.9 \pm 12.2$, $\mathrm{M}: \mathrm{F}=13: 32$; routine diagnostic laboratories, Tehran, Iran). Subjects under the age of 35 years (from all groups), those with peptic ulcers (from Group B), and those with dyspepsia (from Group C) were initially excluded. $H$. pylori infection was determined by serology. The demographic information of our study population is presented in Table 1. Blood samples were collected for serology and isolation of mononuclear cells. Gastric specimens were collected from patients undergoing gastric surgery or endoscopy for determination of gastric histopathology. The patient demographic information, including age, gender, and ethnicity was collected via personal interview (Table 1). The ethnicities of subjects were categorized as Fars (Persian) or non-Fars (Turk, Lor, Kurd, Gilaki, Mazani, etc.). Data and sample collections were carried out according to the protocols approved by the National Committee on Ethical Issues in Medical Research, Ministry of Health and Medical Education of Iran; Ref No. 315. A written informed consent was provided by every participant.

\section{Gastric histopathology}

Gastric specimens were obtained from the proximal (corpus), middle (incisura angularis), and distal (antrum) stomach according to the modified Sydney's method $^{[31]}$. Paraffin-embedded, H\&E (hematoxylin and 
Table 1. Demographic characteristics of the study population

\begin{tabular}{|c|c|c|c|c|c|}
\hline \multirow[b]{2}{*}{ Characteristics } & \multirow[b]{2}{*}{$\begin{array}{c}\text { Gastric Cancer }(\%) \\
\qquad(\mathrm{n}=31)\end{array}$} & \multirow[b]{2}{*}{$\begin{array}{c}\text { Gastritis }(\%) \\
(n=58)\end{array}$} & \multirow[b]{2}{*}{$\begin{array}{c}\text { Controls }(\%) \\
(n=46)\end{array}$} & \multicolumn{2}{|c|}{$P$ values } \\
\hline & & & & $\begin{array}{c}\text { Gastric Cancer } v s . \\
\text { Controls }\end{array}$ & $\begin{array}{c}\text { Gastritis } v s . \\
\text { Controls }\end{array}$ \\
\hline \multicolumn{6}{|l|}{ Age range } \\
\hline Mean \pm SD & $59.4 \pm 11.6$ & $56.5 \pm 9.4$ & $52.9 \pm 12.2$ & 0.027 & 0.144 \\
\hline \multicolumn{6}{|l|}{ Gender } \\
\hline Male & 67.9 & 51.4 & 26.7 & \multirow{2}{*}{0.001} & \multirow{2}{*}{0.025} \\
\hline Female & 32.1 & 48.6 & 73.3 & & \\
\hline \multicolumn{6}{|l|}{ Ethnicity } \\
\hline Fars & 19.2 & 27 & 57.8 & \multirow{2}{*}{0.001} & \multirow{2}{*}{0.007} \\
\hline Non-Fars & 80.8 & 73 & 42.2 & & \\
\hline \multicolumn{6}{|l|}{ Inflammation (Grade) } \\
\hline 0 & - & 2.7 & - & \multirow{5}{*}{-} & \multirow{5}{*}{-} \\
\hline I & - & 43.2 & - & & \\
\hline II & - & 21.6 & - & & \\
\hline III & - & 18.9 & - & & \\
\hline IV & - & 13.5 & - & & \\
\hline \multicolumn{6}{|l|}{ Atrophy (Stage) } \\
\hline 0 & - & 59.5 & - & \multirow{5}{*}{-} & \multirow{5}{*}{-} \\
\hline I & - & 29.7 & - & & \\
\hline II & - & 8.1 & - & & \\
\hline III & - & 2.7 & - & & \\
\hline IV & - & 0 & - & & \\
\hline \multicolumn{6}{|l|}{ Tumor (Subsite) } \\
\hline Cardia & 42.9 & - & - & \multirow{3}{*}{-} & \multirow{3}{*}{-} \\
\hline Non-Cardia & 53.6 & - & - & & \\
\hline Mixed & 3.5 & - & - & & \\
\hline \multicolumn{6}{|l|}{ Tumor (Subtype) } \\
\hline Intestinal & 50 & - & - & & \\
\hline Diffuse & 29.2 & - & - & & \\
\hline Signet ring cell & 4.2 & - & - & - & - \\
\hline Mixed & 8.3 & - & - & & \\
\hline Other & 8.3 & - & - & & \\
\hline Tumor (Stage) & & & & & \\
\hline IA & 4.6 & - & - & & \\
\hline IB & 14.7 & - & - & & \\
\hline II & 19.0 & - & - & 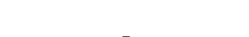 & 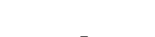 \\
\hline IIIA & 38.1 & - & - & - & - \\
\hline IIIB & 19.0 & - & - & & \\
\hline IV & 4.6 & - & - & & \\
\hline Tumor (Grade) & & & & & \\
\hline Poor & 34.8 & - & - & & \\
\hline Moderate & 30.4 & - & - & - & - \\
\hline Well & 34.8 & - & - & & \\
\hline Serum anti-NapA ant & & & & & \\
\hline Negative & 41.9 & 60.3 & 76.1 & 0003 & ר 00 \\
\hline Positive & 58.1 & 39.7 & 23.9 & 0.005 & 0.02 \\
\hline IL4 -590 Genotype & & & & & \\
\hline $\mathrm{CC}$ & 45.2 & 37.9 & 71.7 & & \\
\hline $\mathrm{T}$ carrier $(\mathrm{CT}+\mathrm{TT})$ & 54.8 & 62.1 & 28.3 & 0.02 & 0.0008 \\
\hline
\end{tabular}


eosin)-stained sections were evaluated for the grade of gastric inflammation (grades 0-IV) and the stage of gastric atrophy (stages $0-\mathrm{IV}$ ), according to the OLGA method of classification ${ }^{[32]}$ (Table 1). Gastric adenocarcinoma patients were categorized based on tumor location (cardia, noncardia, or mixed), histological subtype (intestinal/diffuse/mixed) ${ }^{[33]}$, grade of differentiation (well/moderate/poor) ${ }^{[34]}$, and stage of metastasis ${ }^{[35]}$ (Table 1).

\section{Immunoblotting}

Patients' sera were evaluated for the presence of IgG antibodies against rHP-NAP by Western blotting. Briefly, rHP-NAP was run on $15 \%$ SDS-PAGE, transferred to nitrocellulose membrane and blocked overnight in $2 \%$ skim milk. Diluted patient sera were applied to the membranes. The membranes were reacted with HRP-conjugated anti-human IgG (DAKO, Denmark) and developed by 3,3'-diaminobenzidine (Sigma, USA).

\section{IL-4-590 C/T single nucleotide polymorphism}

In order to detect the $\mathrm{C}$ to $\mathrm{T}$ transition at position -590 in the IL-4 promoter region, PCR-RFLP was carried out using the indicated forward (5'TAAACTTGGGAGAACATGGT -3') and reverse (5'TGGGGAAAGATAGAGTAATA-3') primers. The PCR conditions were as follows: one cycle of initial denaturation $\left(94^{\circ} \mathrm{C}, 3 \mathrm{~min}\right)$, followed by 35 cycles of $94^{\circ} \mathrm{C}(30 \mathrm{~s}), 53.5^{\circ} \mathrm{C}(30 \mathrm{~s}), 72^{\circ} \mathrm{C}(30 \mathrm{~s})$ and terminated by one cycle of final extension $\left(72^{\circ} \mathrm{C}, 3 \mathrm{~min}\right)$, which amplified a 195-bp fragment of the gene. The PCR products were digested with 1 unit of $A v a$ II restriction enzyme (Fermentas, Lithuania) at $37^{\circ} \mathrm{C}$ for 3 hours. The digested products were then run on $3 \%$ agarose gel, and the resulting bands were interpreted as follows: CC: $195 \mathrm{bp}$, TT: $175 \mathrm{bp}+20 \mathrm{bp}$, and CT: 195 bp+175 bp+20 bps. Subjects carrying one (CT) or two (TT) mutant alleles were categorized as $\mathrm{T}$ carriers (CT+TT).

\section{Statistical analysis}

Data analysis was conducted using STATA software (v.12). Statistical associations were calculated by Chisquare $\left(X^{2}\right)$ and fisher's exact tests. Multivariable regression analysis, adjusting for potential confounders (age, gender, and ethnicity), calculated the odd ratios (OR) and 95\% confidence intervals (95\% CI). Probability $(P)$ values were considered statistically significant, if less than 0.05 .
(A)

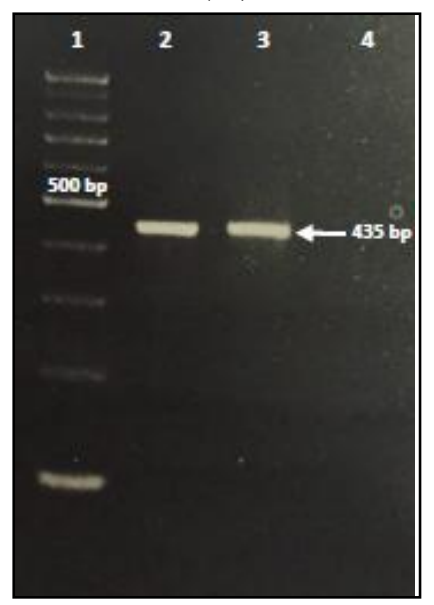

(B)

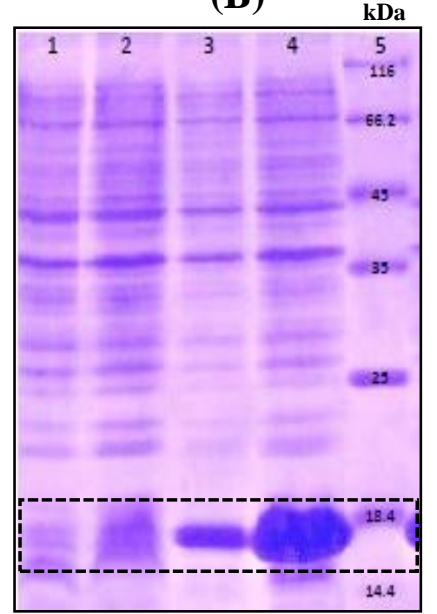

(C)

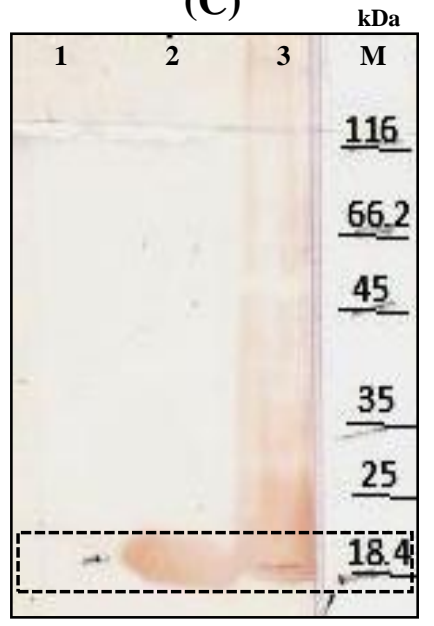

\section{RESULTS}

\section{Production of the recombinant HP-NAP}

The PCR-amplified 435-bp gene fragment encoding rHP-NAP (Fig. 1A) was cloned and subcloned into the linearized pTZ57R and pET23a vectors, respectively. NdeI/XhoI restriction digestion of the recombinant vector released the cloned fragment and therefore confirmed its identity. The cloned fragment was

Fig. 1. Cloning, expression, and identity confirmation of recombinant HP-NAP. (A) PCR amplification of napA gene. Lane 1,100 bp DNA marker; Lanes 2 and 3, H. pylori napA gene; Lane 4, negative control. (B) SDS-PAGE analysis of the expressed HP-NAP protein. Lane 1, pET23a (before induction); Lane 2, pET23a (after induction); Lane 3, pET23a-napA (before induction); Lane 4, pET23a-napA (after induction); Lane 5, the protein size marker. (C) Western blotting using anti-6X His tag antibody. Lane 1, BI (before induction); Lane 2, Sup (bacterial culture supernatant after induction); Lane 3, Pellet (bacterial culture pellet after induction); Lane M, the protein size marker. (D) Western blotting using pooled patient sera. Lane 1, H. pylori-negative; Lane 2,: H. pyloripositive; Lane $\mathrm{M}$, the protein size marker. 
sequenced, and the resulting information was deposited in the GenBank (accession No.: KC616343.1). BLAST analysis of the sequenced coding region confirmed its identity at the genetic level. Determination of its sequence homology with other HP-NAP gene sequences was carried out by BioEdit and Clustal X. The result exhibited $95-100 \%$ nucleotide similarity between our (Iranian) gene sequence and those of $H$. pylori strains from different geographic locations, as well as that of J99 reference strain $(98.3 \%$, data not shown). IPTG induction of BL21 (DE3) E. coli cells harboring HP-NAP-pET28a resulted in the expression of the $\sim 17-\mathrm{kDa}$ recombinant HP-NAP protein (Fig. 1B). The identity of the recombinant protein was confirmed at two levels by Western blotting using anti$6 \mathrm{X}$ His tag antibody (Fig. 1C) and pooled H. pyloripositive sera (Fig. 1D).

\section{Risk of gastritis in HP-NAP sero-positive, IL-4 -590T carriers}

Gastritis patients were evaluated for the grade of inflammation and stage of atrophy (Table 1). Every subject was diagnosed with various grades of gastric inflammation, about $40 \%$ of whom were presented with gastric atrophy. We evaluated our study population for serum antibodies against rHP-NAP and found $39.7 \%$ of gastritis patients as seropositive, compared to only $23.9 \%$ of the $H$. pylori-positive asymptomatic controls $(P=0.02)$. Multivariable regression analysis, adjusting for age, gender, and ethnicity, identified HP-NAP seropositive subjects at 4.62 fold $(\mathrm{OR}=4.62,95 \% \mathrm{CI}=1.50-14.22)$ greater risk of gastritis (Fig. 2A), in reference to HP-NAP seronegative subjects.

In order to detect IL-4 C-590T single nucleotide polymorphism (SNP), genomic DNA was extracted from each subject and underwent PCR-RFLP. The population was categorized into subjects with wild (CC) or mutant ( $\mathrm{T}$ carrier=CT+TT) genotypes. A statistically significant majority of gastritis $(62.1 \%$, $P=0.0008)$ patients were either heterozyote (CT) or homozygote (TT) for IL-4 C-590T SNP, as compared to only $28.3 \%$ of $H$. pylori-positive asymptomatic controls. Multivariable regression analysis identified IL-4-590 T carriers (CT and TT) at a moderately increased risk of gastritis $([\mathrm{OR}=1.76,95 \% \mathrm{CI}=1.24$ 2.49], Fig. 2A). Joint examination of the above mentioned two variables placed double positive (HPNAP-seropositive/-590T carrier) subjects at a 9.7 fold (OR=9.70, 95\% CI=2.06-45.69) amplified risk of gastritis, in reference to double negatives (HP-NAP seronegative/IL-4 -590 CC; Fig. 2A).

\section{Risk of gastric cancer in HP-NAP sero-positive, IL- 4 -590T carriers}

Gastric cancer patients were mostly diagnosed with tumors of the noncardia anatomic subsite $(53.6 \%)$ and intestinal histologic subtype $(50 \%$; Table 1$)$. The above biomarker analysis was also carried out for gastric cancer patients. The significant majority of whom (58.1\%) were seropositive for HP-NAP, as compared to $H$. pylori-positive asymptomatic controls $(23.9 \%$, $P=0.003)$. The projected risk impact for gastric cancer was nearly double $(\mathrm{OR}=9.07,95 \% \mathrm{CI}=1.99-42.0)$ that of gastritis $(\mathrm{OR}=4.62$, 95\% $\mathrm{CI}=1.50-14.22)$ in $\mathrm{HP}$ NAP-seropositive subjects, in reference to HP-NAP seronegative subjects (Fig. 2B).

Overall, $54.8 \%$ of gastric cancer patients carried the IL-4 -590T SNP, which was significantly higher than that of $H$. pylori-positive asymptomatic controls (28.3\%, $P=0.02)$, which again recognized IL-4 -590 T carriers (CT and TT) at a moderately increased risk of gastric cancer $[(\mathrm{OR}=1.63,95 \% \mathrm{CI}=1.05-2.52)$, Fig. 2B).

Co-presence of the above two markers, however, drastically multiplied the odds ratio and placed doublepositive (HP-NAP-seropositive/-590T carrier) subjects at more than 30 fold $(\mathrm{OR}=33.64,95 \% \mathrm{CI}=2.06-548.68)$ increased risk of gastric cancer, as compared to doublenegative (HP-NAP seronegative/IL-4 $-590 \quad$ CC) subjects (Fig. 2B).

\section{DISCUSSION}

Gastric inflammation is a hallmark of Helicobacter pylori infection, from which other $H$. pylori-associated gastrointestinal complications, including gastric cancer are believed to arise ${ }^{[36]}$. Therefore, any variables that exacerbate the gastric inflammatory response could theoretically potentiate the risk of gastric cancer. In this study, we have examined the co-presence of two inflammation-modulating factors, one originating from the infecting organism (HP-NAP) and the other from the host (IL-4C-590T SNP).

HP-NAP is recognized for its ability to activate and recruit neutrophils ${ }^{[3]}$. It can also serve to protect $H$. pylori from the toxic damages inflicted by the inflammatory cells ${ }^{[8,9]}$, as well as to cultivate the bacterium with the resulting by-products ${ }^{[1]}$. The immunogenic properties of HP-NAP have repeatedly nominated it as a putative vaccine candidate ${ }^{[7]}$. Its function in switching the immune response from Th2 to Th1 type has been employed as an adjuvant in Th2type diseases such as asthma ${ }^{[37]}$, and in situ regression of tumors such as that of the bladder ${ }^{[38]}$. Its dual pathogenic/therapeutic functions ${ }^{[3,39]}$ have created the 

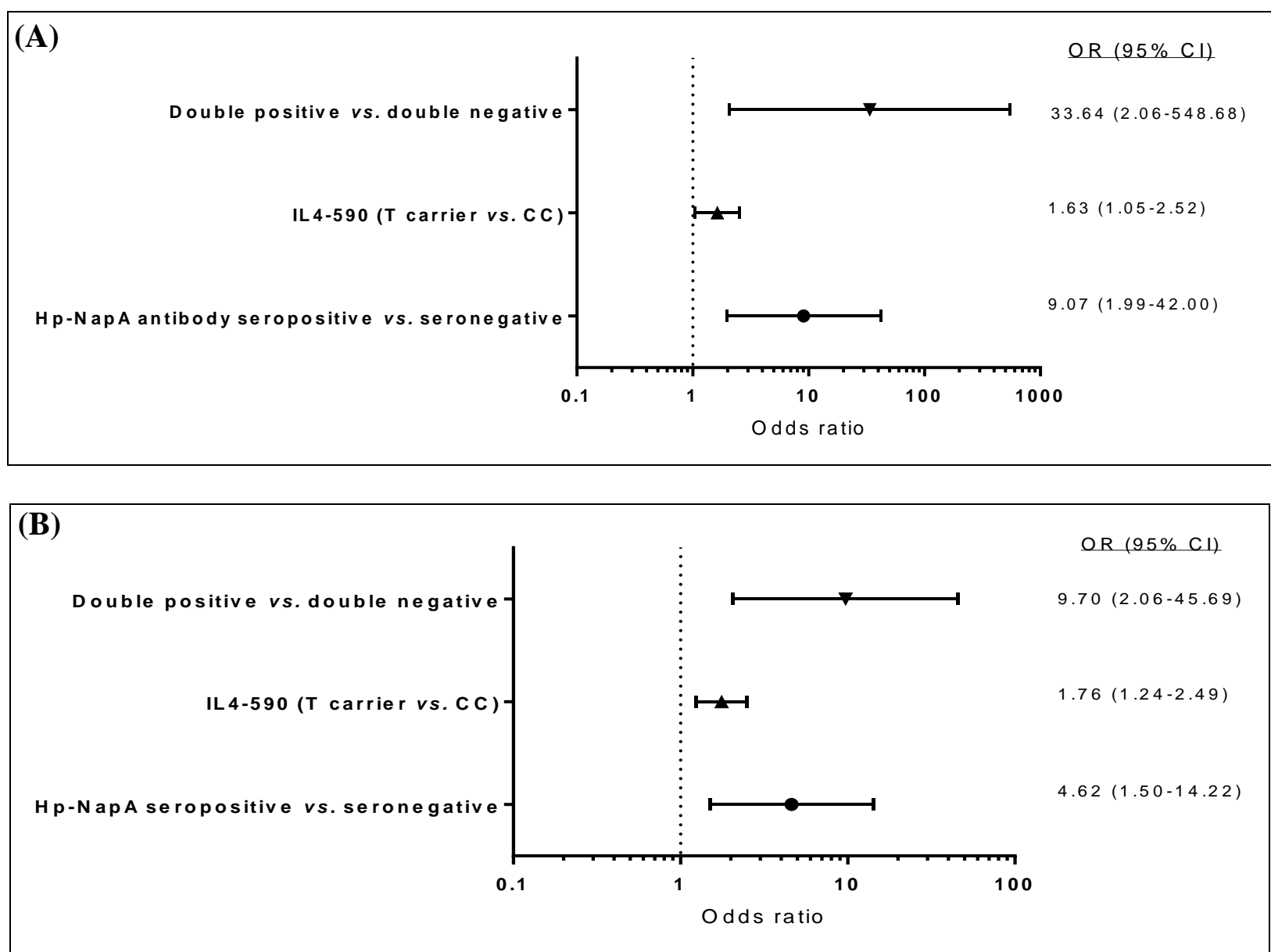

Fig. 2. Forest plots presenting the odds ratio and $95 \%$ confidence intervals for the evaluated biomarker. Odds of developing (A) gastritis or ( B) gastric cancer, in reference to H. pylori-positive asymptomatic controls. Double positive, HP-NAP seropositive/C590T carriers; double negative HP-NAP seronegative/IL-4 -590 CC. All calculations were adjusted for age, gender, and ethnicity.

paradox as to whether its expression in the H. pyloriinfected subjects works to exacerbate or protect against the induced gastrointestinal complications, and whether it can be used as a screening biomarker.

Here, we have examined host HP-NAP-specific antibodies to partly address the above paradox. Our findings, from a case-control study in Iran, demonstrated that subjects with serum antibodies against HP-NAP were at higher risk of developing gastric inflammation (4.6 fold) and to a greater extent, gastric cancer (9.1 fold). Long and colleagues ${ }^{[24]}$ measured the levels of HP-NAP-specific antibodies in various clinical groups of $H$. pylori-infected patients in China and reported a statistically significant step-wise elevation of serum antibodies from healthy subjects (sero-positivity: $27.7 \%$, OD: $0.65 \pm 0.18$ ), to chronic gastritis (sero-positivity: $85.7 \%$, OD: $0.89 \pm 0.14$ ), to gastric cancer (sero-positivity: 97.7\%, OD: 1.01 \pm 0.24 ) patients. Using multiplex serology, Song et al. ${ }^{[23]}$ evaluated serum antibodies specific to $H$. pylori CagA and non-CagA factors for their association with gastric adenocarcinoma in Sweden. Among the non-CagA factors, they found HP-NAP-specific antibodies to project a risk impact of 2.6 fold $(\mathrm{OR}=2.6,95 \%$ CI: 1.7 4.0) for GAC, in general and 3.4 fold (OR=3.4, 95\% CI: 2.1-5.4) for noncardia GAC. Similarly, Liu et $a l .^{[40]}$, using multivariate logistic regression, adjusting for potential confounders (age, gender, smoking, and alcohol drinking), found Chinese HP-NAP seropositive subjects at $9.2(\mathrm{OR}=9.2,95 \% \mathrm{CI}: 1.96-43.14)$ fold increased risk of gastric cancer, in reference to the controls. The most convincing evidence comes from a recent report ${ }^{[41]}$ on a collection of eight cohorts from China, Japan, and Korea (1447 cases and 1801 controls), in which HP-NAP seropositivity placed subjects at a 1.45 (1.26-1.68) fold magnified risk for gastric cancer.

On the other hand, the role of functional single nucleotide gene polymorphisms in inflammationmodulating cytokines have long been associated with the risk of diseases arising from chronic inflammatory backgrounds, including epithelial malignancies such as 
gastric cancer. Here, we have targeted IL-4 C-590T SNP, since previous reports from Asian populations have demonstrated a risk impact for gastric cancer in IL-4 -590T carriers, in reference to the wild genotype. However, this notion was not confirmed by other investigators ${ }^{[29,30]}$. In our study, using multivariable logistic regression, having adjusted for the potential confounders of age, gender, and ethnicity, revealed an estimated 76 and $63 \%$ increased risk of gastritis and gastric cancer in IL-4 -590T carriers, respectively.

Having jointly assessed the above two variables, we found a synergistic amplification of risk, when both variables were present in one individual. Such that double-positive subjects were found at 9.7 fold and 33.6 fold amplified risk of gastritis and gastric cancer, respectively. To our knowledge, there are no previous reports of joint examination of these two biomarkers as risk biomarkers for gastritis or gastric cancer. The main limitation of this study is the small sample sizes, which create a low power (as evident by the broad confidence intervals), when assessing the risk of gastritis or gastric cancer in double positives versus double negatives. Nevertheless, if our results are validated in larger populations, they nominate joint assessment of these two biomarkers as a simple non-invasive, readily accessible tool for screening gastric cancer-at-risk populations. Therefore, larger case-control studies rising from prospective cohorts are recommended to re-examine this hypothesis.

\section{ACKNOWLEDGEMENTS}

This study was generously supported by a technical assistance grant (IRN-072), which was co-funded by the Islamic Development Bank, Saudi Arabia and Pasteur Institute of Iran.

CONFLICT OF INTEREST. None declared.

\section{REFERENCES}

1. Song H, Ekheden IG, Zheng Z, Ericsson J, Nyren O, Ye $\mathrm{W}$. Incidence of gastric cancer among patients with gastric precancerous lesions: observational cohort study in a low risk Western population. BMJ 2015; 351: h3867.

2. Correa P. Human gastric carcinogenesis: a multistep and multifactorial process--first american cancer society award lecture on cancer epidemiology and prevention. Cancer research 1992; 52(24): 6735-6740.

3. de Bernard M, D'Elios MM. The immune modulating activity of the Helicobacter pylori HP-NAP: Friend or foe? Toxicon 2010; 56(7): 1186-1192.

4. Evans DJ Jr, Evans DG, Takemura T, Nakano H,
Lampert HC, Graham DY, Granger DN, Kvietys PR. Characterization of a Helicobacter pylori neutrophilactivating protein. Infection and immunity 1995; 63(6): 2213-2220.

5. Leakey A, La Brooy J, Hirst R. The ability of Helicobacter pylori to activate neutrophils is determined by factors other than $\mathrm{H}$. pylori neutrophil-activating protein. The Journal of infectious diseases 2000; 182(6): 1749-1755.

6. Olczak AA, Wang G, Maier RJ. Up-expression of NapA and other oxidative stress proteins is a compensatory response to loss of major Helicobacter pylori stress resistance factors. Free radical research 2005; 39(11): 1173-1182.

7. Satin B, Del Giudice G, Della Bianca V, Dusi S, Laudanna C, Tonello F, Kelleher D, Rappuoli R, Montecucco C, Rossi F. The neutrophil-activating protein (HP-NAP) of Helicobacter pylori is a protective antigen and a major virulence factor. The journal of experimental medicine 2000; 191(9): 1467-1476.

8. Olekhnovich IN, Vitko S, Chertihin O, Hontecillas R, Viladomiu M, Bassaganya-Riera J, Hoffman PS. Mutations to essential orphan response regulator HP1043 of Helicobacter pylori result in growth-stage regulatory defects. Infection and immunity 2013; 81(5): 1439-1449.

9. Wang G, Hong Y, Olczak A, Maier SE, Maier RJ. Dual Roles of Helicobacter pylori NapA in inducing and combating oxidative stress. Infection and immunity 2006; 74(12): 6839-6846.

10. Petersson C, Forsberg M, Aspholm M, Olfat FO, Forslund T, Boren T, Magnusson KE. Helicobacter pylori SabA adhesin evokes a strong inflammatory response in human neutrophils which is down-regulated by the neutrophil-activating protein. Medical microbiology and immunology 2006; 195(4): 195-206.

11. Tonello F, Dundon WG, Satin B, Molinari M, Tognon G, Grandi G, Del Giudice G, Rappuoli R, Montecucco C. The Helicobacter pylori neutrophil-activating protein is an iron-binding protein with dodecameric structure. Molecular microbiology 1999; 34(2): 238-246.

12. Ceci P, Mangiarotti L, Rivetti C, Chiancone E. The neutrophil-activating Dps protein of Helicobacter pylori, HP-NAP, adopts a mechanism different from Escherichia coli Dps to bind and condense DNA. Nucleic acids research 2007; 35(7): 2247-2256.

13. Chiumiento L, Del Prete G, Codolo G, De Bernard M, Amedei A, Della Bella C, Piazza M, D'Elios S, Caponi L, D'Elios MM, Bruschi F. Stimulation of TH1 response by Helicobacter pylori neutrophil activating protein decreases the protective role of $\mathrm{IgE}$ and eosinophils in experimental trichinellosis. International journal of immunopathology and pharmacology 2011; 24(4): 895903.

14. D'Elios MM, Codolo G, Amedei A, Mazzi P, Berton G, Zanotti G, Del Prete G, de Bernard M. Helicobacter pylori, asthma and allergy. FEMS immunology and medical microbiology 2009; 56(1): 1-8. 
15. Del Prete G, Chiumiento L, Amedei A, Piazza M, D'Elios MM, Codolo G, de Bernard M, Masetti M, Bruschi F. Immunosuppression of $\mathrm{TH} 2$ responses in Trichinella spiralis infection by Helicobacter pylori neutrophil-activating protein. The Journal of allergy and clinical immunology 2008; 122(5): 908-913.

16. Codolo G, Mazzi P, Amedei A, Del Prete G, Berton G, D'Elios MM, de Bernard M. The neutrophil-activating protein of Helicobacter pylori down-modulates Th2 inflammation in ovalbumin-induced allergic asthma. Cellular microbiology 2008; 10(11): 2355-2363.

17. D'Elios MM, Amedei A, Cappon A, Del Prete G, de Bernard M. The neutrophil-activating protein of Helicobacter pylori (HP-NAP) as an immune modulating agent. FEMS immunology and medical microbiology 2007; 50(2): 157-164.

18. Amedei A, Cappon A, Codolo G, Cabrelle A, Polenghi A, Benagiano M, Tasca E, Azzurri A, D'Elios MM, Del Prete G, de Bernard M. The neutrophil-activating protein of Helicobacter pylori promotes Th1 immune responses. The Journal of clinical investigation 2006; 116(4): 1092-1101.

19. Michel A, Pawlita M, Boeing H, Gissmann L, Waterboer T. Helicobacter pylori antibody patterns in Germany: a cross-sectional population study. Gut pathogens 2014; 6: 10.

20. Michel A, Waterboer T, Kist M, Pawlita M. Helicobacter pylori multiplex serology. Helicobacter 2009; 14(6): 525-535.

21. Tang RX, Luo DJ, Sun AH, Yan J. Diversity of Helicobacter pylori isolates in expression of antigens and induction of antibodies. World journal of gastroenterology 2008; 14(30): 4816-4822.

22. Yan J, Mao YF, Shao ZX. Frequencies of the expression of main protein antigens from Helicobacter pylori isolates and production of specific serum antibodies in infected patients. World journal of gastroenterology 2005; 11(3): 421-442.

23. Song H, Michel A, Nyren O, Ekstrom AM, Pawlita M, Ye W. A CagA-independent cluster of antigens related to the risk of noncardia gastric cancer: associations between Helicobacter pylori antibodies and gastric adenocarcinoma explored by multiplex serology. International journal of cancer 2014; 134(12): 29422950.

24. Long M, Luo J, Li Y, Zeng FY, Li M. Detection and evaluation of antibodies against neutrophil-activating protein of Helicobacter pylori in patients with gastric cancer. World journal of gastroenterology 2009; 15(19): 2381-2388.

25. Wang SK, Zhu HF, He BS, Zhang ZY, Chen ZT, Wang $\mathrm{ZZ}, \mathrm{Wu}$ GL. CagA+ $\mathrm{H}$ pylori infection is associated with polarization of $\mathrm{T}$ helper cell immune responses in gastric carcinogenesis. World journal of gastroenterology 2007; 13(21): 2923-2931.

26. Orsini B, Vivas JR, Ottanelli B, Amedei A, Surrenti E, Galli A, Milani S, Pinzani P, Del Prete G, Surrenti C, Baldari CT, Touati E, D' Elios MM. Human gastric epithelium produces IL-4 and IL-4delta2 isoform only upon Helicobacter pylori infection. International journal of immunopathology and pharmacology 2007; 20(4): 809-818.

27. Imran M, Laddha NC, Dwivedi M, Mansuri MS, Singh J, Rani R, Gokhale RS, Sharma VK, Marfatia YS, Begum R. Interleukin-4 genetic variants correlate with its transcript and protein levels in patients with vitiligo. The British journal of dermatology 2012; 167(2): 314323.

28. Sun Z, Cui Y, Jin X, Pei J. Association between IL-4 590C $>$ T polymorphism and gastric cancer risk. Tumour biology: the journal of the international society for oncodevelopmental biology and medicine 2014; 35(2): 1517-1521.

29. Zhang C, Huang JY, He ZQ, Weng H. Genetic association between interluekin-4 rs2243250 polymorphism and gastric cancer susceptibility: evidence based on a meta-analysis. OncoTargets and therapy 2016; 9: 2403-2408.

30. Wang T, Tian L, Gao M, Song H, Wei Y, Xue Y. Interleukin (IL)-4 $-590 \mathrm{C}>\mathrm{T}$ polymorphism is not associated with the susceptibility of gastric cancer: An updated meta-analysis. Annals of medicine and surgery 2016; 9: 1-5.

31. Dixon MF, Genta RM, Yardley JH, Correa P. Classification and grading of gastritis. The updated Sydney System. International Workshop on the Histopathology of Gastritis, Houston 1994. The American journal of surgical pathology 1996; 20(10): 1161-1181.

32. Rugge M, Meggio A, Pennelli G, Piscioli F, Giacomelli L, De Pretis G, Graham DY. Gastritis staging in clinical practice: the OLGA staging system. Gut 2007; 56(5): 631-636.

33. Lauren P. THE two histological main types of gastric carcinoma: diffuse and so-called intestinal-type carcinoma. an attempt at a histo-clinical classification. Acta pathologica et microbiologica scandinavica 1965; 64: 31-49.

34. Martin IG, Dixon MF, Sue-Ling H, Axon AT, Johnston D. Goseki histological grading of gastric cancer is an important predictor of outcome. Gut 1994; 35(6): 758763.

35. Sobin LH, Fleming ID. TNM Classification of malignant tumors, fifth edition (1997). Union Internationale Contre le Cancer and the American Joint Committee on Cancer. Cancer 1997; 80(9): 1803-1804.

36. Zhang W, Lu H, Graham DY. An Update on Helicobacter pylori as the Cause of Gastric Cancer. Gastrointestinal tumors 2014; 1(3): 155-165.

37. Liu X, Fu G, Ji Z, Huang X, Ding C, Jiang H, Wang X, Du M, Wang T, Kang Q. A Recombinant DNA plasmid encoding the sIL-4R-NAP fusion protein suppress airway inflammation in an OVA-induced mouse model of asthma. Inflammation 2016; 39(4): 1434-1440.

38. Codolo G, Munari F, Fassan M, de Bernard M. Evaluation of the efficacy of the H. pylori protein HP- 
NAP as a therapeutic tool for treatment of bladder cancer in an orthotopic murine model. Journal of visualized experiments : JoVE 2015;(99): e52743.

39. Fu HW. Helicobacter pylori neutrophil-activating protein: from molecular pathogenesis to clinical applications. World journal of gastroenterology 2014; 20(18): 5294-5301.

40. Liu J, Liu H, Zhang T, Ren X, Nadolny C, Dong X, Huang L, Yuan K, Tian W, Jia Y. Serum Helicobacter pylori NapA antibody as a potential biomarker for gastric cancer. Scientific reports 2014; 4: 4143.

41. Cai H, Ye F, Michel A, Murphy G, Sasazuki S, Taylor PR, Qiao YL, Park SK, Yoo KY, Jee SH, Cho ER, Kim J, Chen SC, Abnet CC, Tsugane S, Cai Q, Shu XO, Zheng W, Pawlita M, Epplein M. Helicobacter pylori blood biomarker for gastric cancer risk in East Asia. International journal of epidemiology 2016; 45(3): 774781. 